\title{
IDENTIFICATION OF ANISOTROPIC CRITERIA FOR STRATIFIED SOIL BASED ON TRIAXIAL TESTS RESULTS
}

\author{
MATYLDA TANKIEWICZ, MAREK KAWA \\ Wrocław University of Science and Technology, Wybrzeże Wyspiańskiego 27, 50-370 Wrocław, Poland, \\ e-mail: matylda.tankiewicz@pwr.edu.pl
}

\begin{abstract}
The paper presents the identification methodology of anisotropic criteria based on triaxial test results. The considered material is varved clay - a sedimentary soil occurring in central Poland which is characterized by the so-called "layered microstructure". The strength examination outcomes were identified by standard triaxial tests. The results include the estimated peak strength obtained for a wide range of orientations and confining pressures. Two models were chosen as potentially adequate for the description of the tested material, namely Pariseau and its conjunction with the Jaeger weakness plane. Material constants were obtained by fitting the model to the experimental results. The identification procedure is based on the least squares method. The optimal values of parameters are searched for between specified bounds by sequentially decreasing the distance between points and reducing the length of the searched range. For both considered models the optimal parameters have been obtained. The comparison of theoretical and experimental results as well as the assessment of the suitability of selected criteria for the specified range of confining pressures are presented.
\end{abstract}

Key words: strength, anisotropy, varved clay, Pariseau criterion, weakness plane

\section{INTRODUCTION}

It is well known that modeling the strength anisotropy of geomaterials is a very important issue in the design of geotechnical structures. Although the significance of anisotropy is often ignored and undermined, in many cases it can have a far greater influence on the failure mechanism than some other factors, such as the orientation of principal stress vectors [14]. Strength anisotropy is usually introduced into modeling using the anisotropic strength criterion. The identification of this criterion is not an easy task. The choice of the adequate model strongly depends on the type of the considered material and the identification of its parameters needs to be based on tests performed on differently oriented samples.

The materials with anisotropic strength include sedimentary rocks and soils, such as sandstones, shales and varved clays. For these materials strength anisotropy is associated with the occurrence of the socalled "layered microstructure" or "stratification" and usually they are referred to as transversally isotropic (i.e. isotropic in the planes of lamination). Many researchers investigated the strength anisotropy of sedimentary materials, particularly of rocks [8], [11]. A brief review of the existing anisotropic criteria for this class of media was presented in [2].
Among sedimentary materials varved clay is especially difficult to describe. In this soil a typical layered structure is strongly irregular, which is the consequence of the formation process. The soil is formed in glacial lakes as a result of the periodical melting of glaciers. During warm periods deposits are carried into a lake where first coarser particles sediment composing light sandy-silty varves. Then, in subsequent cold periods fine particles precipitate forming dark silty-clayey varves. Changes in sedimentation conditions result in the variability of the composition and thickness of the layers [10] and in the disturbance of structure [13]. The investigations of varved clay and its mechanical properties, but without considering the impact of layering orientation, were conducted for example in papers [1], [3], [5].

The present article focuses on the identification of the parameters of failure criteria for varved clay from central Poland based on the results of triaxial tests. Two models were selected as potentially adequate for the description of varved clay strength, namely Pariseau [9] and its conjunction with the Jaeger weakness plane model [4], [6]. The procedure of criteria identification employs a variant of the least squares method. To find an optimal solution for each parameter a wide range of values were analyzed. The presented procedure appears to be quite effective and allows for the assessment of the suitability of selected criteria to describe the strength of tested soil. 


\section{SELECTED ANISOTROPY MODELS}

The study is based on the results of triaxial tests made on varved clay occurring near Bełchatów, a city in central Poland, presented earlier in [8] and [12]. The triaxial test outcomes include the peak value of the principal stress $\sigma_{1}$ of the material determined for 7 different sample orientations of $\alpha$, i.e. $0^{\circ}, 15^{\circ}, 30^{\circ}$, $45^{\circ}, 60^{\circ}, 75^{\circ}, 90^{\circ}\left(0^{\circ}\right.$ means horizontal and $90^{\circ}$ vertical lamination) and for 6 different confining pressures $\sigma_{3}$, i.e., $50 \mathrm{kPa}, 200 \mathrm{kPa}, 400 \mathrm{kPa}, 600 \mathrm{kPa}, 800 \mathrm{kPa}$, $1000 \mathrm{kPa}$. The results presented in the cited works show that the strength of the tested soil exhibits strong anisotropy and the barotropy effect.

The analysis of the material structure was introduced by [13]. The SEM and microtomography tests revealed that the thickness of a separate varves is strongly variable and the contact area between the layers is quite complex, the smooth transition of one varve into another or a corrugated contact line can be observed. Also the stratification of the material turned out to be not planar, but curved. Such features affect both the strength and failure mechanisms of the mate-
Among the existing anisotropy models the one proposed by Pariseau [9] was selected for the identification. The reason was twofold. First, the Pariseau model, as the frictional extension of the Hill criterion, provides the strength dependence on confining pressure. Second, the model is mathematically continuous, which results in a smooth, differentiable failure function. This appears to be consistent with the obtained strength results.

The general form of the Pariseau model can be expressed as:

$$
A_{i j} \sigma_{i j}+\left(A_{i j k l} \sigma_{i j} \sigma_{k l}\right)^{n / 2}-1 \leq 0,
$$

where $A_{i j}$ and $A_{i j k l}$ are anisotropic material tensors, $\sigma_{i j}$ and $\sigma_{k l}$ denote stress tensors and $n$ is the additional material constant, for geomaterials usually assumed as 1 (as in the present work). As it was mentioned before, varved clay consists of two constituents forming alternating layers and it is usually featured as a transversely isotropic material. Taking into account the transversal isotropy of soil tensors $A_{i j}$ and $A_{i j k l}$ presented in the material direction can be expressed using five material constants $F, G, M, U, V$ as:

$$
A_{i j}=\left[\begin{array}{ccc}
U & 0 & 0 \\
& V & 0 \\
\text { sym. } & & V
\end{array}\right],
$$

$$
A_{i j k l}=\left[\begin{array}{ccccc}
2 G & -G & -G & 0 & 0 \\
& F+G & -F & 0 & 0 \\
& & F+g & 0 & 0 \\
& & & M / 2 & 0 \\
& & & & M / 2 \\
& & & & \\
& & & &
\end{array}\right.
$$

rial. Typically the failure mechanism for a layered material involves localized shearing in the layer of a weaker component. This mechanism usually reveals itself in the results as a quantitatively different failure function obtained for some range of orientations [6]. In the case of tested soil, the slipping along a weaker constituent has also been observed. However, the results do not clearly reveal the appearance of such two functions. It is probably due to the similarity in the composition of both types of layers as well as a distorted structure which, on average, results in a smoother failure function.

$$
\left.\begin{array}{lccc}
0 & 0 & 0 & 0 \\
0 & 0 & 0 & 0 \\
0 & 0 & 0 & 0 \\
0 & M / 2 & 0 & 0 \\
0 & 0 & M / 2 & 0 \\
+G) / 2 & 0 & 0 & (2 F+g) / 2 \\
& M / 2 & 0 & 0 \\
& & M / 2 & 0 \\
& & & (2 F+g) / 2
\end{array}\right] .
$$

Since the mechanism of slipping along the weaker constituent was present in the experimental study, an alternative description incorporating localized shearing by expanding the Pariseau criterion was investigated. The modification comprises the introduction of the single family of a weakness plane. The combination of the Pariseau criterion and the weakness plane approach was proposed in paper [6]. It assumes that the material is transversely isotropic and composed of the matrix described by the Pariseau criterion and a set of parallel weakness planes. The model is schematically 
shown in Fig. 1. Assuming that the planes of weakness are described by the Drucker-Prager criterion, the weakness plane strength can be expressed in terms of the components of the stress vector on this plane $\left\{\sigma_{11}, \sigma_{12}, \sigma_{13}\right\}$ as:

$$
\sqrt{\sigma_{12}^{2}+\sigma_{13}^{2}}+\left(3 a \sigma_{11}-c\right) / \sqrt{1-12 a^{2}} \leq 0,
$$

where $a$ is a parameter associated to the angle of internal fraction and $c$ is the cohesion of the weakness plane.

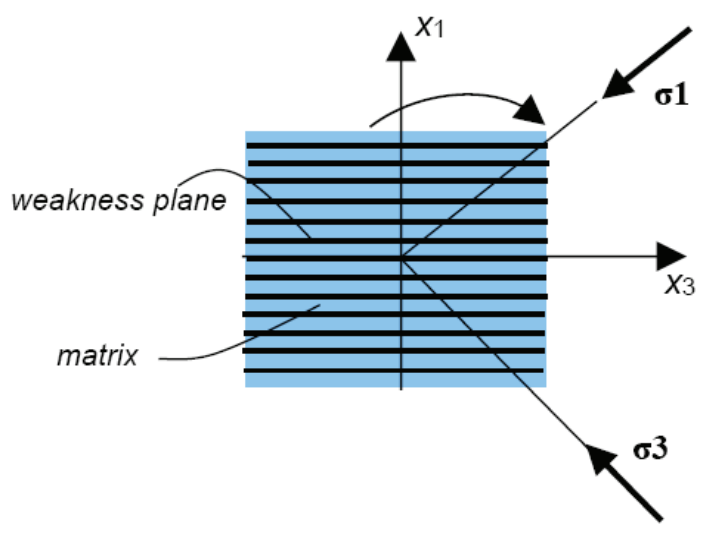

Fig. 1. Model: Pariseau matrix with the singular plane of weakness

\section{IDENTIFICATION PROCEDURE}

As it has been shown in the previous paragraph, the Pariseau model is characterized by five independent material constants. Classically, the parameters of the criterion are identified based on the uniaxial compression and tension test performed for material directions (in the case of stratified soil perpendicular and parallel to the stratification direction) and one additional uniaxial compression test performed in the direction inclined at an angle of $45^{\circ}$ from the material directions [2]. However, in the case of varved clay this procedure of identification can be difficult to apply. The uniaxial tests (both tension and compression ones) in the case of soft soils are subjected to significant errors. Due to this, in the present study the material constants for the Pariseau criterion were obtained by fitting the model to the experimental results (both the model and data were normalized with suitable confining pressure).

The identification procedure is based on the least squares method. In order to determine the differences between the experimental data and fitted model (residuals), it is necessary to calculate the values of strength based on the criterion for all considered ori- entations and confining pressures. The criterion in material directions (1) and (2) can be simplified to the following form:

$$
\begin{gathered}
{\left[F\left(\sigma_{33}-\sigma_{22}\right)^{2}+G\left(\left(\sigma_{11}-\sigma_{33}\right)^{2}+\left(\sigma_{22}-\sigma_{11}\right)^{2}\right)\right.} \\
\left.+(2 G+4 F) \sigma_{23}^{2}+2 M\left(\sigma_{31}^{2}+\sigma_{12}^{2}\right)\right]^{1 / 2} \\
+U \sigma_{11}+V\left(\sigma_{22}+\sigma_{33}\right)-1=0 .
\end{gathered}
$$

The principal directions of loading for any other orientation than $0^{\circ}$ and $90^{\circ}$ differ from the material ones. In order to use the criterion in form (4), the measured values of stress $\sigma_{1}$ and confining pressure $\sigma_{3}$ need to be transformed to material directions. This can be done using classical transformation formulas:

$$
\begin{gathered}
\sigma_{11}=\sigma_{1} \cos ^{2} \alpha+\sigma_{1} \sin ^{2} \alpha, \\
\sigma_{22}=\sigma_{3} \cos ^{2} \alpha+\sigma_{1} \sin ^{2} \alpha \\
\sigma_{33}=\sigma_{3}, \\
\sigma_{12}=\sigma_{21}=\left(\sigma_{1}-\sigma_{3}\right) \cos \alpha \sin \alpha \\
\sigma_{13}=\sigma_{31}=0, \\
\sigma_{23}=\sigma_{32}=0,
\end{gathered}
$$

incorporating orientation angle $\alpha$ defined in Fig. 2 . After substituting formulas (5) into (4) the criterion based strength values for assumed $U, V, G, F, M$ can be generated.

Due to the strong non-linearity of the criterion, the optimal values were searched for by checking points that divided the search range into 30 equal intervals. The initial bounds of the searching interval for each parameter was established in preliminary tests. Due to the large number of parameters, the procedure turned out to be quite time consuming. The computations were carried out in stages. In all the stages, for each parameter, 31 points, spaced equally from lower to upper bound, were checked. In the subsequent stages the accuracy of calculations was increased by reducing the length of the searched range to about half of its length in comparison with the previous stage (with the center on a new range set for the value of the parameter with the minimal number of the sums of squares obtained in the previous stage). The computations were conducted to the point where the further reduction of intervals between the checked values of parameters did not result in a significant decrease in the sum of squared residuals (about ten stages). The code written in the Matlab environment took about 4.5 hours of computation time in one stage using a modern PC. 
The same computations were made for the conjunction of Pariseau (4) and the weakness plane criteria (3). For that case, the criterion based values were calculated as the minimum of both models. Because the model introduces two additional parameters of the critical plane, the computing time using a procedure analogous to the previous one considerably increased. If 31 values had been checked in every stage for each parameter, the calculations would have lasted about 5 months. Due to this, a smaller number of values (21) was assumed, and the calculation time was 10 days.

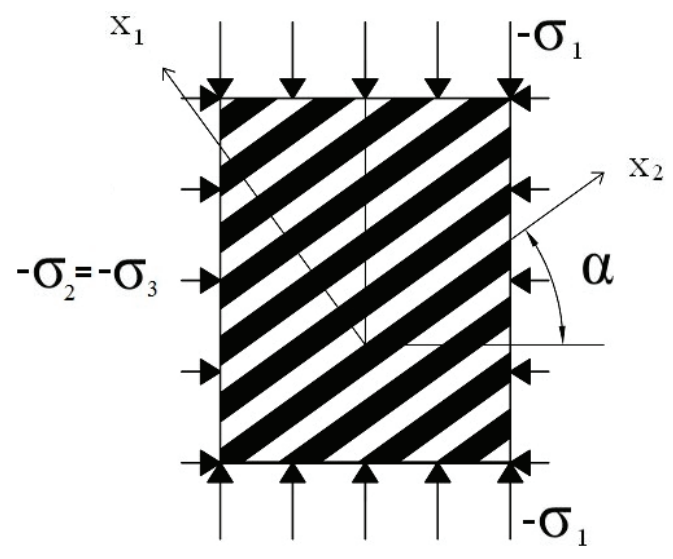

Fig. 2. Principal load direction during the test and orientation angle $\alpha$

\section{RESULTS}

The described technique was applied for the identification of both models. First, the Pariseau criterion was examined. The Pariseau model assumes the linear relation between strength and confining pressure. In the case of soil this dependence is true for relatively small confinement ranges. The examined range of confining pressure is wide, from $50 \mathrm{kPa}$ to $1000 \mathrm{kPa}$. For this range no satisfactory result was obtained. The comparison of the identified criterion (dashed line) and experimental data are presented in Fig. 3. The graph shows the results as absolute values. The minimal sum of residual squares was equal to 5.56 (which seems to be a reasonable value), but the diagrams show that for almost all confining pressures the strength was either underestimated or overestimated. However, after excluding the lowest confinement, the sum of squares in the range of 200 to $1000 \mathrm{kPa}$ decreased to 2.07 and the satisfactory agreement between the experimental results and the identified model (continuous line in Fig. 3) was obtained. The value is lower partially due to the smaller amount of data to fit, however, the sum of squares obtained for the same range for parameters fitting all confinements equals 3.99, which indicates much worse fitting. Since the description obtained for higher confining pressures is qualitatively much better without fitting $50 \mathrm{kPa}$, this confinement was finally excluded from the identification data set of the Pariseau criterion. It should be noted that the sum of squared residuals calculated for all confining pressures using the values of the parameters obtained for the range of 200 to $1000 \mathrm{kPa}$ equals 28.46. Although this number is much larger than the initially obtained value of 5.56 , it seems that this is mainly the consequence of strength normalization. As the fitted results are normalized with confining pressure, the residuals for smaller confining pressure (which was divided by a smaller number) have greater impact on the sum of residual squares. A large increase in the summary value indicates that the results for the pressure value $50 \mathrm{kPa}$ strongly deviate from the linear trend obtained for the other of the outcomes. Thus, the strength of the material cannot be assumed as linearly dependent on confining pressure in the full range of confinement. The bounds assumed for Pariseau parameters are presented in Table 1. The optimal values were obtained with three significant digits of accuracy as:

$$
\begin{gathered}
U=0.00306, \quad V=0.00143, \quad G=0.0000434, \\
F=0.0000056, \quad M=0.000172 .
\end{gathered}
$$

It can be observed that the final identification of the Pariseau model for the lowest confinement $(50 \mathrm{kPa})$ gives much higher values of strength than the ones observed in the experiment. This indicates that one needs to be very careful when applying this model in the case of small loads. For the higher confinement the obtained agreement is satisfactory. It should be remembered that varved clay is a soil with complex and varying structure, hence specific results may vary from the main trend.

Table 1. The bound set of Pariseau parameters

\begin{tabular}{|c|c|c|c|c|c|}
\hline & $U[-]$ & $V[-]$ & $G[-]$ & $F[-]$ & $M[-]$ \\
\hline Lower limit & 0.002 & 0.001 & 0.00002 & 0.000005 & 0.0001 \\
\hline Upper limit & 0.005 & 0.004 & 0.00005 & 0.000008 & 0.0004 \\
\hline
\end{tabular}

Subsequently, the conjunction of the Pariseau and the single weakness plane criterion was identified. The preliminary tests showed that the plane of weakness does not affect the strength for most confining pressures. The plane is active only for the confining pressure of $50 \mathrm{kPa}$. Therefore, it was decided that the best fit could be obtained by combining the 

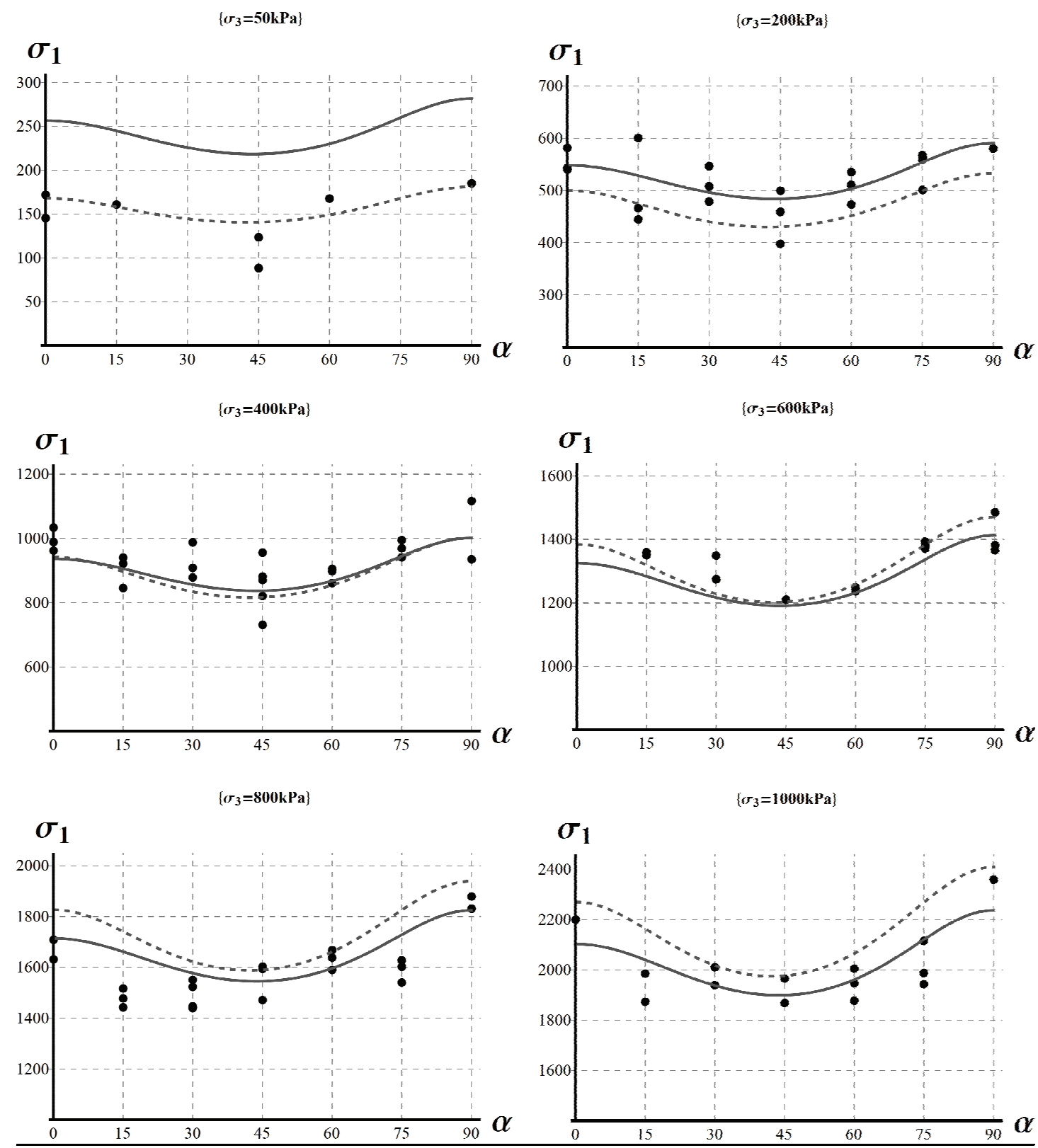

Fig. 3. Comparison of the Pariseau criterion with the experimental data.

Points - experimental results, dashed line - identification in range 50-1000 kPa of confining pressure, continuous line - identification of confining pressure in the range of $200-1000 \mathrm{kPa}$

Table 2. The bound set of the plane of weakness parameters

\begin{tabular}{|c|c|c|}
\hline & $a[-]$ & $c[\mathrm{kPa}]$ \\
\hline Lower limit & 0.0 & 0 \\
\hline Upper limit & 0.5 & 100 \\
\hline
\end{tabular}

parameters of the Pariseau criterion estimated in the range of 200 to $1000 \mathrm{kPa}$ and the plane of weakness estimated in its full range. Thus, the material constants of the Pariseau model are the same as earlier. The bounds assumed for critical plane parameters $a$ and $c$ are shown in Table 2. The optimal values for these parameters were obtained as $c=1 \mathrm{kPa}, a=0.13$. The outcomes are presented in Fig. 4. Taking into consideration the planes of weakness reduces the sum of residual squares in the full range of confinement from 28.46 to 18.83 . As can be seen in the figure, the quality of description obtained for $50 \mathrm{kPa}$ is still not satisfactory. The number 18.83 is again much larger than 5.56 obtained for the Pariseau criterion fitting the full range of confinements. As it has already been pointed out, the increase in the sum of squares is mainly the effect of strong qualitative differences in the results 

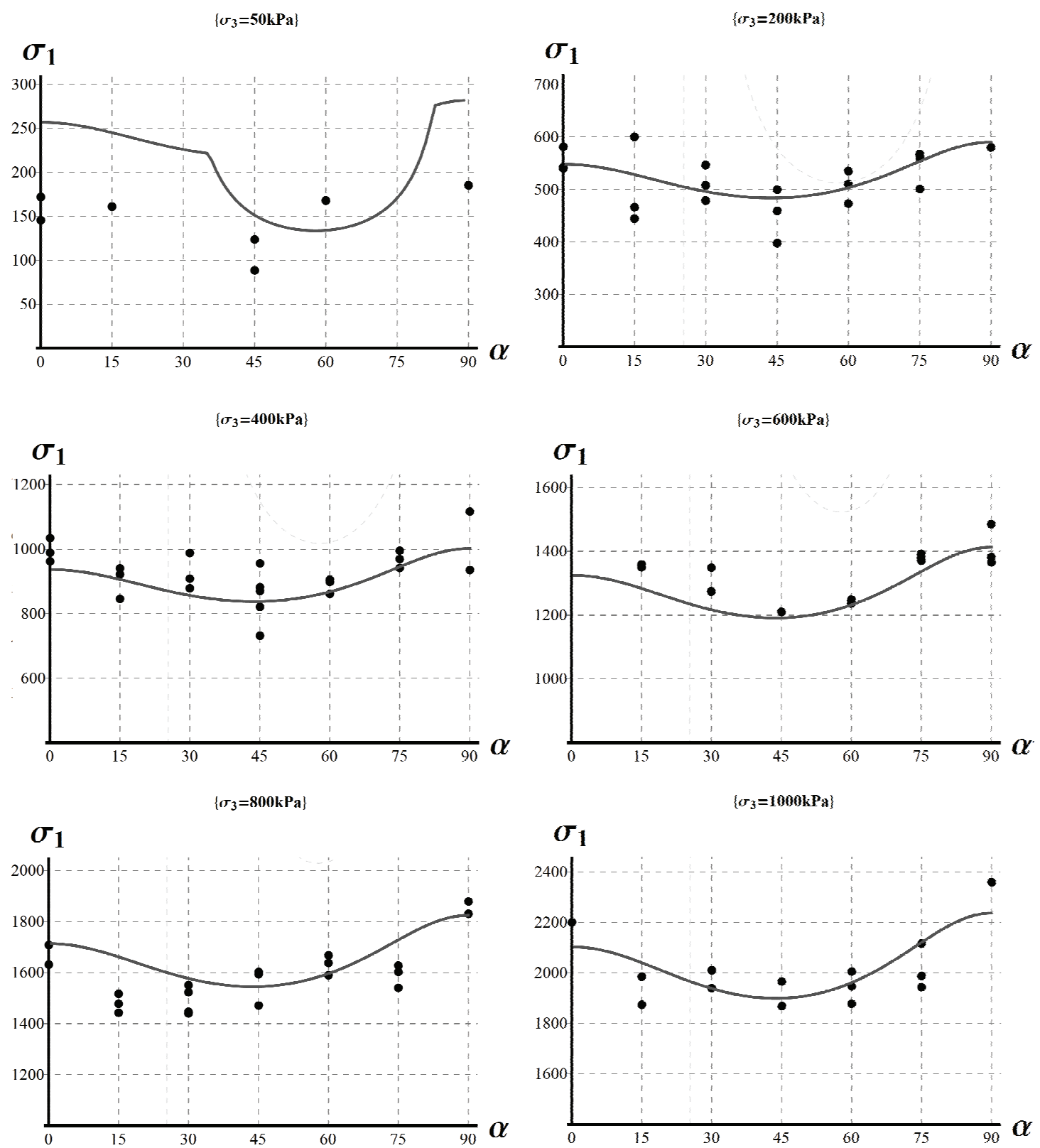

Fig. 4. Comparison of the Pariseau criterion with a single weakness plane (continuous line) with the experimental data (points)

obtained at $50 \mathrm{kPa}$ in comparison with all other results.

\section{CONCLUSIONS}

In the paper the identification of anisotropic criterion for varved clay based on triaxial test results has been presented. The Pariseau model as well as its conjunction with the weakness plane criterion was assumed as adequate to describe the strength of the material. The used procedure employs the least square method. The optimal values of parameters are searched for by sequential dividing of a specified range of values. During the identification procedure, apart from quantitative conditions, the focus of attention was on the quality of the obtained agreement between the identified model and the fitted data. As it has been shown for the specified range of confining pressures, a satisfactory agreement can be obtained for both selected models.

The following conclusions can be drawn from the paper:

i) The presented procedure allows to identify the chosen model in a satisfactory manner. It uses 
all available data (instead of tests performed in a specified direction), which in the case of complicated anisotropic materials seems to be an adequate approach. The procedure is universal and can be used for other models and materials, but in the case of large number of parameters, the computation time increases considerably. The MATLAB codes are available to interested readers upon request (please contact the corresponding author).

ii) The presented results show that the Pariseau criterion is an appropriate model for the strength prediction of soft layered soil, such as varved clay, for most of the considered confinements. As the linear relation between compressive strength and confining pressures does not seem to be always valid, the application of the Pariseau model for lower confining pressures is limited.

iii) The introduction of weakness planes to the anisotropic criterion improves the description of material strength for lowest confining pressures. Nevertheless, the description obtained for these pressures is not fully satisfactory. Also the strength results do not reveal the influence of the "slip over a weaker component" (associated with the weakness plane criterion and present in many sedimentary materials), although the mechanism was observed in the experiment. This is probably due to similarities in the structure and grain composition of neighboring varves and the irregularities in layering.

Since varved clay is a complex material and its structure can vary strongly from point to point, the findings ii) and iii) might not be applicable for all varved clays. Although the presented identification is based on a significant number of triaxial tests, the scatter of test results for the specific case (orientation and confining pressure) is quite large (see Figs. 3 and 4). This shows that the results of identification should be used with great caution.

\section{REFERENCES}

[1] De Groot D.J., Lutenegger A.J., Characterization by sampling and in-situ testing Connecticut Valley varved clay, Studia Geotechnica et Mechanica, 2005, 27(3-4), 107-120.

[2] Duveau G., Shao J.F., Henry J.P., Assessment of some failure criteria for strongly anisotropic geomaterials, Mechanics of Cohesive-frictional Materials, 1998, 3(1), 1-26.

[3] Florkiewicz A., Kostrzewski W., O interpretacji badań $i$ opisie wytrzymałości osadów (iłów) warwowych, Zeszyty Naukowe Politechniki Poznańskiej, 1995, Nr 40, 9-20.

[4] JAEGER J.C., Shear failure of anisotropic rocks, Geological Magazine, 1960, 97(01), 65-72.

[5] LU Y., TAN Y., LIN G., Characterization of thick varvedclayey-silt deposits along the Delaware River by field and laboratory tests, Environmental earth sciences, 2013, 69(6), 1845-1860.

[6] ŁyDżBa D., Kawa M., Failure mechanism of sedimentary rocks: micromechnics approach, 2nd International Symposium On Computational Geomechanics (COMGEO II), 2011, 27-29.

[7] ŁydżBa D., Pietruszczak S., Shao J.F., On anisotropy of stratified rocks: homogenization and fabric tensor approach, Computers and Geotechnics, 2003, 30(4), 289-302.

[8] ŁydżBa D., Tankiewicz M., Preliminary study of failure anisotropy characterization of varved clay, AGH Journal of Mining and Geoengineering, 2012, 36, 229-234.

[9] PARISEAU W.G., Plasticity theory for anisotropic rocks and soils, 10th US Symposium on Rock Mechanics (USRMS), American Rock Mechanics Association, 1968, 267-295.

[10] Petterson G., Renberg I., Geledi P., Lindberg A., LINDGREN F., Spatial uniformity of sediment accumulation in varved lake sediments in northern Sweden, Journal of Paleolimnology, 1993, 9(3), 195-208.

[11] PietruszczaK S., ŁydżBa D., Shao J.F., Modelling of inherent anisotropy in sedimentary rocks, International Journal of Solids and Structures, 2002, 39(3), 637-648.

[12] TANKIEWICZ M., Badania laboratoryjne kierunkowej wytrzymałości gruntu warstwowego, Inżynieria Morska i Geotechnika, 2015, 3, 316-319.

[13] TANKIEWICZ M., Structure investigations of layered soil-varved clay, Annals of Warsaw University of Life Sciences - SGGW, Land Reclamation, 2016, 48(4), 365-375.

[14] WATSON J.M., VAKILI A., JAKUBOWSKI M., Rock strength anisotropy in high stress conditions: a case study for application to shaft stability assessments, Studia Geotechnica et Mechanica, 2015, 37(1), 115-125. 